\title{
Apuntes crítico textuales a los Cynegetica de Opiano de Apamea
}

\author{
Sebastián Martínez García \\ Institut Can Vilumara \\ smartin4@xtec.cat \\ ORCID iD: https://orcid.org/0000-0002-0685-0386
}

\section{Tomás Silva Sánchez}

\author{
Universidad de Cádiz \\ tomas.silva@uca.es
}

ORCID iD: https://orcid.org/0000-0002-5380-5959

\section{Text-critical Notes on Oppian of Apamea’s Cynegetica}

\begin{abstract}
Este trabajo consiste en una serie de propuestas crítico textuales a los Cynegetica de Opiano de Apamea: I 147, 197, 235, 464; II 8; III 21, 152, 360, 394; IV 156, 198, 295.

Palabras clave: Opiano de Apamea; Cynegetica; crítica textual.

This paper consists of some textual notes on Oppian of Apamea's Cynegetica: I 147, 197, 235, 464; II 8; III 21, 152, 360, 394; IV 156, 198, 295.

Key words: Oppian of Apamea; Cynegetica; textual criticism.

Cómo citar este artículo / Citation: Martínez García, Sebastián y Silva Sánchez, Tomás 2020: «Apuntes crítico textuales a los Cynegetica de Opiano de Apamea», Emerita 88 (1), pp. 143-167.
\end{abstract}

El poema didáctico sobre caza titulado Cynegetica $^{1}$, obra de un poeta de finales del s. II d.C. conocido como Opiano de Apamea o Ps.-Opiano ${ }^{2}$, ha sido objeto de dos ediciones críticas modernas: la primera, a cargo de P. Bou-

${ }^{1}$ Este trabajo ha sido realizado en el marco del Proyecto I+D FFI2017-85015-P, financiado por el MINECO.

2 Sobre este poeta, su biografía y la manera de denominarlo, cf. Silva Sánchez 2002, pp. 15-25 y Martínez y Silva Sánchez 2003.

Copyright: (C) 2020 CSIC. Este es un artículo de acceso abierto distribuido bajo los términos de la licencia de uso y distribución Creative Commons Reconocimiento 4.0 Internacional (CC BY 4.0). 
dreaux, fue publicada en 1908; la segunda, a cargo de M. Papathomopoulos, lo fue en $2003^{3}$. Papathomopoulos tuvo muy en cuenta las aportaciones crítico textuales de Mersinias 1999 y Silva Sánchez 2002 ${ }^{4}$. Otras aportaciones recientes dignas de mención son las de Giomi 2003, Cipolla 2006 y, sobre todo, las de G. Agosta en su reseña de la edición de Papathomopoulos y en sus Ricerche, en los que comenta y edita los vv. 1 a 175 del libro II 5 .

1. C. $I 147^{6}$

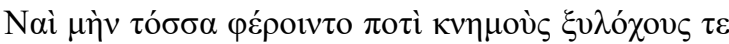

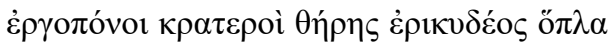

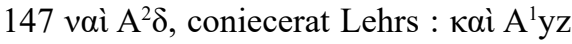

Tras el extenso proemio del canto I (vv. 1-80), Opiano de Apamea se ocupa de los aspectos preliminares de la caza, entre los cuales se encuentra una enumeración a modo de catálogo de los instrumentos necesarios para su práctica (vv. 147-157).

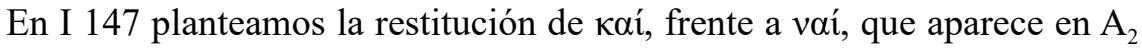
según el aparato crítico de Boudreaux y también, según el de Papathomopoulos, en el grupo $\delta$ (formado por los mss. CDEFXY). No obstante, es preciso puntualizar que, de acuerdo con la colación de Zumbo 1981, sabemos que en el ms. Y se lee kaí y no vaí, y lo mismo en el ms. C, según hemos comprobado $^{7}$. Boudreaux y Papathomopoulos editan vaí, lectura ya conjeturada por Lehrs 1837, p. 323, y estimada correcta por Schmitt 1969, p. 100. Lehrs y Schmitt se apoyan en que vaì $\mu$ ív es empleado doce veces en los Cynegetica ${ }^{8}$.

3 Para las ediciones anteriores del poema, cf. Boudreaux 1908, pp. 3-7; Silva Sánchez 2002, pp. 65-80. Respecto a la valía de la edición de Boudreaux, véase la síntesis realizada por Silva Sánchez 2002, pp. 60-64, y, para la de Papathomopoulos, véase Bartley 2004. Más crítico con esta edición se muestra Agosta 2009a.

${ }^{4}$ Así lo reconoce el editor en la Praefatio, cf. Papathomopoulos 2003, p. XX.

5 Agosta 2009a y 2009b. Hay que citar también Agosta 2003, 2005. Una justa valoración de las aportaciones de Agosta 2009b se lee en la reseña de Martínez 2010.

${ }^{6}$ En cada uno de los casos que estudiamos damos el texto según lo edita Papathomopoulos 2003, acompañado del aparato crítico correspondiente.

${ }^{7}$ Además de en los mss. Y y C, nosotros hemos podido comprobar que кaí es la lectura que dan $\mathrm{A}, \mathrm{C}, \mathrm{G}, \mathrm{H}, \mathrm{I}, \mathrm{K}, \mathrm{L}, \mathrm{M}$, mientras que vaí aparece en $\mathrm{E}$ y F.

${ }^{8}$ Cf. C. I 62, 316, 358, 455; II 176, 315, 506; III 84, 170, 449, 482; IV 433. 
Por su parte, Schneider 1813 edita kaí y, probablemente siguiendo el texto de este último, también Mair 1928.

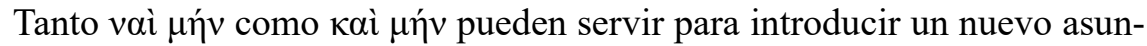
to, bien en una serie, bien tras pausa fuerte ${ }^{9}$ como en nuestro pasaje, en el que, dentro de una amplia sección sobre los aspectos preliminares de la caza, se tratará sobre las armas del cazador de los vv. 147 a 157. Este último seg-

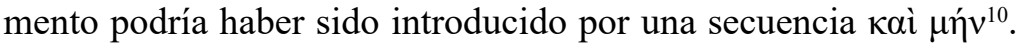

Pero con independencia de los aspectos sintácticos, la cuestión fundamental es, creemos, la confianza que merezcan las aportaciones de $\mathrm{A}_{2}$ y las de los códices del grupo $\delta$. La secunda manus de A, fechada en el s. XIII, corrige el texto del Venet. Marc. gr. 479 (coll. 881), añade en el margen versos omitidos y anota variantes entre líneas ${ }^{11}$; sus lecturas pertenecen a la familia $\mathrm{z}^{12}$. En cuanto a cómo aparece la lectura en cuestión en el ms. A, hemos comprobado que se lee una $\mathrm{N}$ a la izquierda, en el margen, a la al-

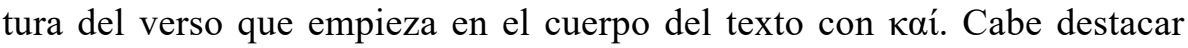
que Boudreaux recoge veintiocho lectiones singulares de $\mathrm{A}_{2}$, de las que admite en su texto cuatro ${ }^{13}$. Por su parte, Papathomopoulos, aparte de las reunidas por Boudreaux, recoge veintidós lecturas exclusivas de $\mathrm{A}_{2}$, de las cuales edita únicamente dos ${ }^{14}$.

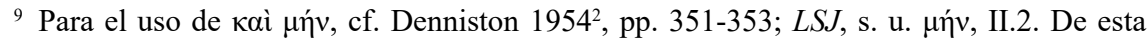

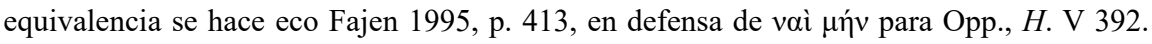

${ }_{10}$ Del mismo modo que sirve para introducir personajes en Hom., Od. XI 582 y XI 593 (dentro del catálogo de personajes que encontró Odiseo en el Hades) y en A.R. I 69, 146, 161 y 199 (en el elenco de héroes que se presentaban para acompañar a Jasón).

${ }^{11}$ Al respecto, cf. Boudreaux 1908, p. 26; Mioni 1985, p. 421; Silva Sánchez 2002, p. 31.

${ }^{12}$ Cf. Boudreaux 1908, p. 38; Silva Sánchez 2002, p. 56. Papathomopoulos 2003, p. VIII, no se pronuncia sobre la filiación de $\mathrm{A}_{2}$, si bien del stemma codicum (ibid. p. XIX) se deduce que está emparentada exclusivamente con algún antecedente del ms. K.

${ }_{13}$ Boudreaux desecha las lectiones únicas de $\mathrm{A}_{2}$ en $C$. I 30, 34, 51, 66, 74, 97, 103, 160 , 292, 294, 310, 320, 329; II 81, 89, 424; III 76, 128, 255; IV 177, 208, 246, 249, 419. Las acepta en C. I 213, II 430, III 212, IV 119 (al menos ésta no sería exclusiva de $\mathrm{A}_{2}$, puesto que también se halla en L, cf. app. crit. de Papathomopoulos). No obstante, han sido refutadas las de C. I 213 (cf. Rebmann 1918, pp. 18-19; Schmitt 1969, p. 129; Giangrande 1973, p. 87; Benedetti 1973, p. 503; Silva Sánchez 2002, pp. 107-108; Papathomopoulos también la rechaza) y $C$. III 212 (cf. Silva Sánchez 2002, pp. 170-171, cuyos argumentos acepta Papathomopoulos).

${ }^{14}$ Las lectiones que añade Papathomopoulos se encuentran en $C$. I 325, 356, 411, 424, 471, 497; II 333, 501, 602, 623; III 1, 21, 40, 217, 498; IV 171, 245, 248, 250, 322. Las descarta todas. Sólo edita las que se encuentran en I 425 y IV 240. 
A su vez, los mss. del grupo $\delta$, cuya datación exacta ha sido polémica en algún caso, no son anteriores al s. $\mathrm{XV}^{15} \mathrm{y}$, por regla general, no aportan lecturas singulares valiosas ${ }^{16}$. Y supra hemos comentado que en el caso que nos ocupa no hay unanimidad para la lectio vaí en los mss. de dicho grupo.

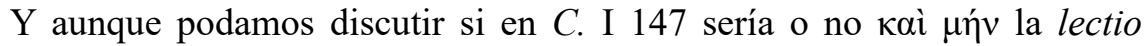
difficilior, porque sea la única vez que aparece en el poema, o porque parez-

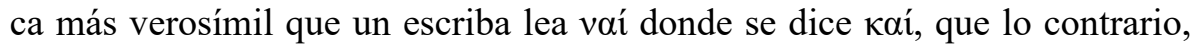
insistiremos en el valor de los mss. como argumento principal. Diríamos además que preferir vaí implicaría oponerse a las reglas que suelen aplicarse a las divergencias entre manuscritos ${ }^{17}$ : ni $\mathrm{A}_{2}$ ni el grupo $\delta$, separadamente $\mathrm{o}$ en conjunto, son los mejores representantes de la tradición manuscrita de los Cynegetica ni dan las lecturas más antiguas (los manuscritos considerados potiores son A en la familia $\mathrm{x}$, a la que pertenece el grupo $\delta$, y K en la familia $\mathrm{z}$, con la que entronca $\mathrm{A}_{2}$ ). De acuerdo con el aparato crítico de Papathomopoulos, son sólo tres las lecturas comunes que en exclusiva presentan $\mathrm{A}_{2}$ y $\delta$, en su conjunto o parcialmente, y todas son rechazadas por el editor griego $^{18}$. Por último, no debe olvidarse la tendencia correctora, ya señalada, de la secunda manus de A.

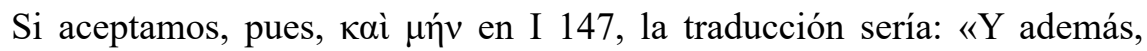
éstas debieran llevar consigo a montes y boscajes los laboriosos y fuertes cazadores como armas de la gloriosa caza».

\section{C. $I 197$}

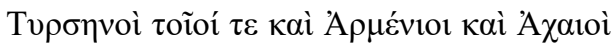

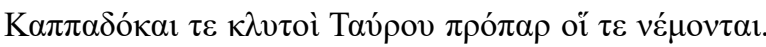

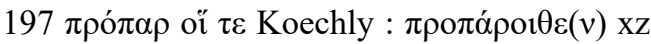

Tras aconsejar que se lleven a la caza caballos machos (I 158-165) y enumerar las razas más notables (I 166-172), el poeta describe el físico ideal

${ }_{15}$ Para la cuestión, cf. Silva Sánchez 2002, pp. 38 y 44 respectivamente.

${ }^{16}$ Sólo seis lecturas singulares de estos seis mss. han sido incluidas en el texto de Papathomopoulos (en C. I 440; II 15, 242, 299, 575 y III 101, atestiguadas por todos los códices del grupo $\delta$, salvo la segunda presente únicamente en el ms. F).

${ }_{17}$ Como las que ofrece en su conocido Manual el prof. Bernabé 1992, pp. 84-87.

${ }^{18}$ Véase el app. crit. correspondiente a C. I 180, II 342 y IV 244. 
de estos animales (I 173-197), determinando unas condiciones que cumplen especialmente los caballos tirrenos, armenios, aqueos y capadocios (versos que reproducimos).

En C. I 197, en lugar de $\pi \rho 0 \pi \alpha ́ \rho o t \theta \varepsilon(v)$, lectio de los mss., Koechly propuso la corrección $\pi \rho \delta \pi \rho \rho$ oï $\tau \varepsilon^{19}$, que así editaron Boudreaux y Mair, en tanto que Papathomopoulos la varió ligeramente ${ }^{20}$. Un primer argumento para defender $\pi \rho \circ \pi \alpha ́ \alpha o t \theta \varepsilon(v)$ sería que se encuentra en ocho ocasiones en los $C y$ negetica (I 256, 482; II 115, 216, 362, 431; III 244; IV 371), por ningún ejemplo de $\pi \rho o ́ \pi \alpha \rho$. Amén de este dato, consideramos que no hay necesidad de modificar el texto, si atendemos a una adecuada comprensión de su sintaxis. Un paralelo muy a tener en cuenta es $C$. III 348-352, que compara los rasgos físicos de la tigresa con los de la leona mediante una serie de frases introducidas por $\tau$ oĩos:

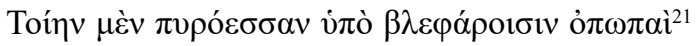

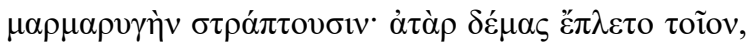

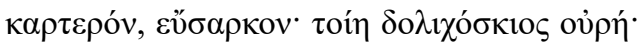

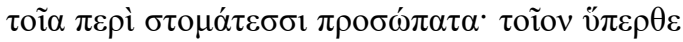

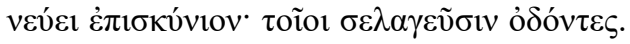

Como vemos, estas oraciones, en su mayoría iniciadas de manera anafó-

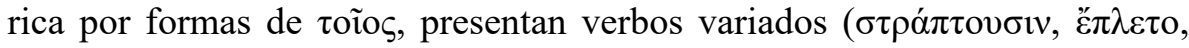

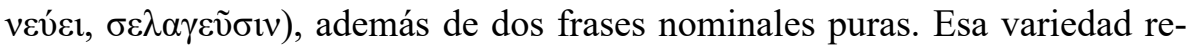
sulta semejante al pasaje que nos ocupa, en cuyo v. 196 el verbo no es expre-

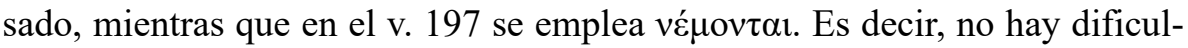

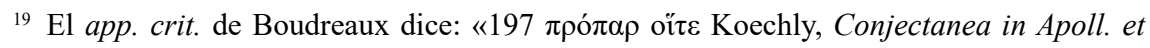
Opp., p. 325 : $\pi \rho \circ \pi \alpha ́$ ó $\theta \varepsilon(v)$ mss». Koechly publicó su trabajo en 1838. Además, sabemos

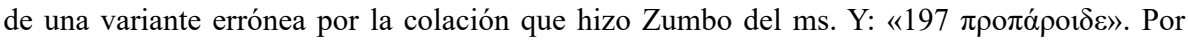
lo demás, en los mss. que hemos consultado (A, C, E, F, G, H, I, K, L, M) sólo se lee la forma $\sin v$ efelcística.

${ }^{20}$ Schmitt 1969, p. 125 también mostró su acuerdo. La aportación de Koechly, caso de haber sido necesaria, habría sido interesante, ya que $\pi \rho{ } \pi \alpha \rho$ coincide con $\pi \rho \circ \pi \alpha ́ \rho o t \theta \varepsilon$ en su valor adverbial (A., Supp. 791, A. 1019; Iul., Caes. 11) y su uso preposicional (aparece sólo en Hes., Th. 518; A.R. I 454, IV 1288), pues ya observaron los antiguos (Hdn.Gr., 2.575.26 Lentz) que $\pi \rho{ }^{\prime} \pi \alpha \rho$ es apócope de $\pi \rho \pi_{\alpha} \rho \rho \imath \theta \varepsilon$. Por otra parte, hubiera sido un buen paralelo

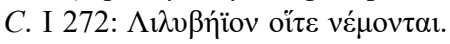

${ }^{21} \omega \dot{\pi}$ o $\pi \alpha i ̀$ al final del v. 348 en la edición de Papathomopoulos es, a todas luces, una errata. 
tad para la combinación de frases nominales puras y frases con verbo explícito en las series introducidas por $\tau$ oĩos, aunque en este caso la mayor parte se desarrolla en una construcción asindética. También, creemos, en el caso que nos interesa, el cambio de verbo o su aparición después de frases nominales puras da pie a una variatio en una estructura paralela ${ }^{22}$.

Explicada de este modo la frase, queda por resolver su traducción. Entre las versiones latinas, anteriores a la corrección de Koechly, Turnèbe 1555 tra-

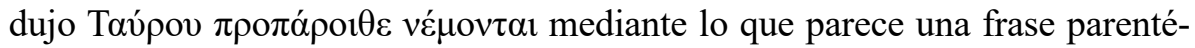
tica: «Tyrrhenique tales, atque Armenii, et Achaei, Cappadocesque praeclari, ante Tauru (monte) pascuntur». Esto es, «tales son los tirrenos, los armenios, los aqueos y los ínclitos capadocios (éstos pacen al pie del Tauro)»» ${ }^{23}$. Se podría

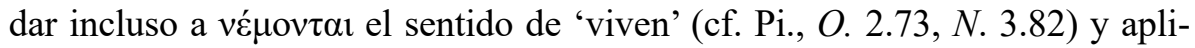
carlo a todas las razas mencionadas en estos versos, traduciendo «tales viven los tirrenos, los armenios, los aqueos y junto al Tauro los ínclitos capadocios». Con todo, entendemos que mediante la repetición de «tales» es como mejor se refleja la sintaxis y el orden del original. Podría sumarse a esta forma de entender el verso el hecho de que, según hemos comprobado, algunos manuscritos presentan un signo ortográfico al final del verso anterior, como tratando de aislar este verso ${ }^{24}$ : «Tales son los tirrenos, los armenios y los aqueos, y tales pacen junto al Tauro los ínclitos capadocios».

\section{C. I 235}

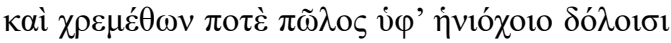

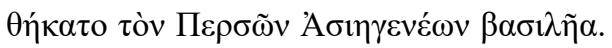

$235 \tau$ òv $\mathrm{K}^{1}: \tau \tilde{\omega} v \mathrm{yK}^{2} \mathrm{LM}$

${ }^{22}$ Cf. también Nic., Th. 780 s., donde una frase nominal pura se halla coordinada con otra con verbo conjugado, de manera que queda roto el paralelismo que podría esperarse de la aná-

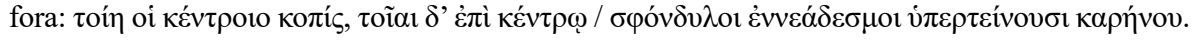

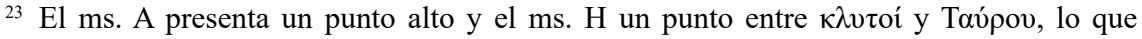
apoyaría esta interpretación. Curiosamente, Schneider 1776 tradujo ya usando una frase de relativo: «Cappadocesque praeclari, qui ante Taurum pascuntur»; y también D. Peiffer en su versión más libre, que se reproduce en Schneider 1813: «tales, qui pabula carpunt infesti circum nemorosa cacumina Tauri, Cappadoces celeres». Coinciden con esta posibilidad, la de la frase de relativo, pero ya siguiendo la corrección de Koechly, Mair 1928, Calvo Delcán 1990 y L'Allier 2009 en sus respectivas traducciones.

${ }^{24} \mathrm{C}$ (punto alto), E (punto), F (coma), I (coma), L (coma), M (punto alto). 
Al encomiar la virtuosa naturaleza de los caballos, el poeta hace referencia a Janto, uno de los corceles de Aquiles (I 226-228), a Bucéfalo (I 229 s.), a los potros nacidos de las yeguas de Erictonio y a Pegaso (I 231-233). Alude también a una célebre anécdota (I $234 \mathrm{~s}$.): la elección de Darío como rey de los persas gracias al relincho de su caballo, reacción provocada por la astucia de su palafrenero Ébares ${ }^{25}$.

En C. I 235 Papathomopoulos elige la forma dada por $\mathrm{K}_{1}$, de manera que el artículo determina a $\beta \alpha \sigma i \lambda \tilde{\eta} \alpha$. También editó $\tau$ óv Boudreaux, aunque no a partir del ms. K, sino de una emendatio de Brunck recogida en Schneider $1776^{26}$. A nuestro entender, es preferible la lectura mayoritaria de los manuscritos $\tau \tilde{\omega} v$,

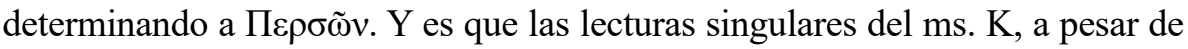
que en determinadas ocasiones son preferibles ${ }^{27}$, en otras resultan discutibles ${ }^{28}$. Por otra parte, es conocido el empleo sin artículo de $\beta \alpha \sigma i \lambda \varepsilon v ́ \varsigma$ en prosa y verso para hacer referencia, como aquí, al rey de Persia ${ }^{29}$. En $C$. I $235 \beta \alpha \sigma \imath \lambda \tilde{\eta} \alpha$, creemos, no precisaría la determinación de un artículo, y, de hecho, pocos versos antes el mismo término es empleado sin él, referido a un rey no menos cono-

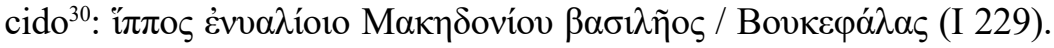

${ }^{25}$ Cf. Ctes. 688F13 Jacoby; Hdt. III 84-87; Trog. Ius. I 10. Véase también Schmitt 1969, pp. 135-136.

${ }^{26}$ Así lo recoge en el app. crit: «235 tòv Schneider ${ }^{1}$, Brunck in ms. Paris. S. gr. 383, f. 27

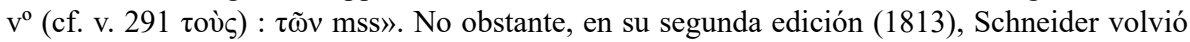
a la lectura de los manuscritos, en lo cual fue seguido por Mair 1928.

${ }^{27}$ El valor de K fue ensalzado por Ludwich 1910, cols. $261 \mathrm{~s}$.

${ }^{28}$ Lo probaría el que, tomando de ejemplo sólo el libro I, lectiones singulares de $\mathrm{K}$ son rechazadas por Boudreaux pero aceptadas por Papathomopoulos: cf. I 89, 91, 101, 137, 143 (bis), 155 (bis), 178, 206, 278, 421, 431; un caso excepcional es I 184, pues es Boudreaux quien prefiere K. En ese mismo libro las únicas lectiones singulares aceptadas por ambos están en I 164, 275 (aquí se pueden leer dos cosas distintas en K) y 519; Papathomopoulos edita incluso alguna otra lectura singular ausente en el app. crit. de Boudreaux, en I 172, 470 (bis) y 488.

${ }^{29}$ Cf. $L S J$, s. u. $\beta \alpha \sigma i \lambda \varepsilon v ́ \varsigma$, III. En prosa cf. p. ej. Hdt. VII 174 o el pasaje ya citado (III 84-87) sobre la llegada al trono de Darío); Th. VIII 48. En verso A., Pers. 5; Ar., Ach. 61. Sería un sustantivo perteneciente a la categoría de los nomina unica, que no requieren, al menos en prosa, el artículo (cf. p. ej. Schwyzer $1966^{3}$, p. 24; Humbert $1972^{3}$, p. 46; Rodríguez Adrados 1992, p. 353; Basile 2001, p. 86); en cambio, los gentilicios se usan habitualmente con artículo cuando tienen valor genérico o colectivo (cf. p. ej. Humbert $1972^{3}$, p. 48).

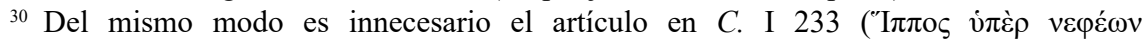

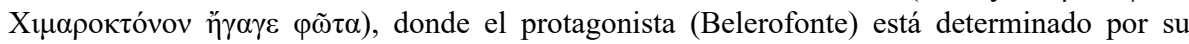
fama. 
La lectura mayoritaria de los mss. es refrendada, pues, por los usos de la lengua griega y de los propios Cynegetica. La traducción de estos dos versos podría ser: «y una vez con sus relinchos un corcel, mediante las añagazas de un palafrenero, instauró al rey de los asiáticos persas».

\section{C. I 464}

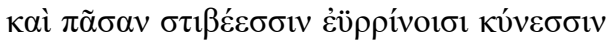

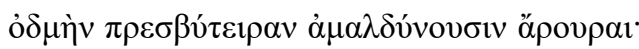

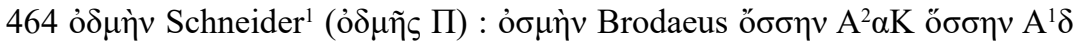

En el pasaje dedicado al rastreo (I 451-467) Opiano señala dos variedades, la realizada por hombres, que siguen las presas valiéndose de la vista, y la que llevan a cabo los perros mediante el olfato. Mientras que aquélla encuentra su mejor época en el invierno, el rastreo canino se desarrolla con dificultad durante la primavera y fácilmente en otoño.

En $C$. I 464, verso relativo a las dificultades que acarrea para los perros la primavera, los códices, como se puede apreciar por el aparato crítico de Papathomopoulos, dan lecturas inadecuadas en este contexto (ö $\sigma \sigma \eta v, ~ o ̋ \sigma \sigma \eta v$, ő $\rceil \eta$, ő $\sigma \tau \eta v)^{31}$. De las modificaciones propuestas, la más antigua, ỏ $\sigma \mu \eta ́ v$, aportación de Brodaeus, es aceptada por Schneider 1813, Boudreaux y Mair. Sin embargo el propio Schneider había propuesto en 1776 ỏ $\mu \eta \dot{v}$, la solución editada por Papathomopoulos y, a nuestro entender, preferible a ỏ $\sigma \mu \eta \dot{v}$.

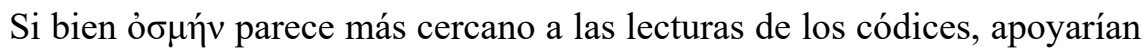
la propuesta de Schneider, de una parte, la Paráfrasis del poema ( $\tau \tilde{\Upsilon} \varsigma \tau \tilde{\omega} v$ $\theta \eta \rho \tilde{\omega} v$ ỏ $\delta \mu \tilde{\eta} \varsigma)$, como se recoge en el aparato crítico $^{32}$, y, de otra, el que ỏ $\delta \mu \eta ́$ y no ỏouŕ sea el término empleado en $C$. I 253, 512, IV 67 y 224, en ningún

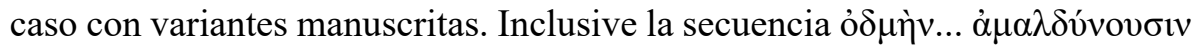

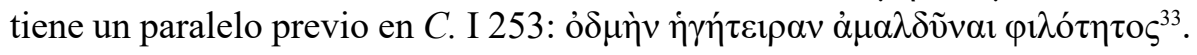

31 Obtenemos esta información del aparato crítico de Boudreaux, más detallado: «464

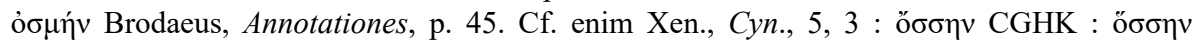

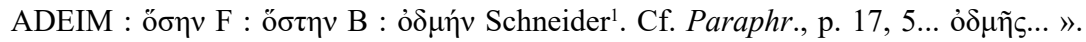

32 Para la Paráfrasis en relación con la tradición manuscrita de los Cynegetica, cf. Boudreaux 1908, pp. 33-36; Papathomopoulos 2003, p. XVII.

${ }^{33}$ Tal vez por editar $\alpha \dot{v} \alpha \lambda \delta \tilde{\eta} v \alpha \_$en $C$. I 253, Boudreaux no captó el parecido con I 464. Para la defensa de la lectura $\dot{\alpha} \mu \alpha \lambda \delta \tilde{v} v \alpha$ en I 253, cf. Silva Sánchez 2002, pp. 110-111. 
Además, ỏ $\sigma \mu \eta ́$ es término inusitado en la épica ${ }^{34}$, frente a ỏ $\delta \mu \eta ́$, atestiguado antes del apamense en Homero, Apolonio de Rodas, Nicandro y Opiano de Cilicia $^{35}$. Interesa en particular A.R. IV 112, donde hallamos otro paralelo para

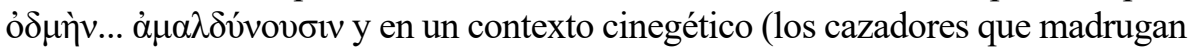

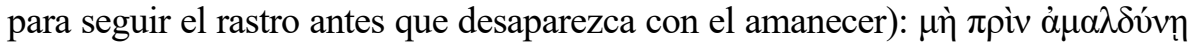

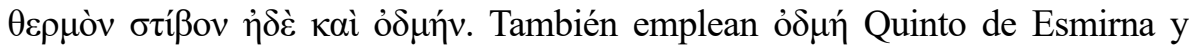

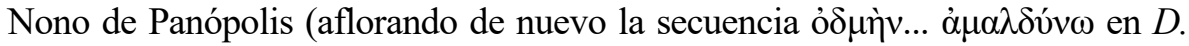

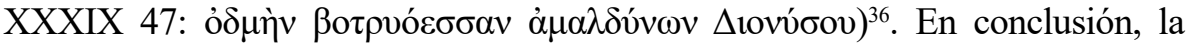
corrección de Schneider parece preferible, y así traducimos: «Y los labrantíos disimulan todo olor, embajada ante los perros rastreadores de buen olfato».

\section{C. II 8}

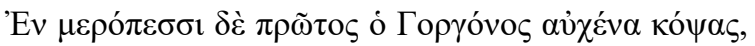

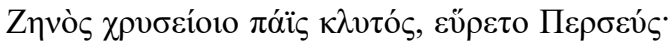

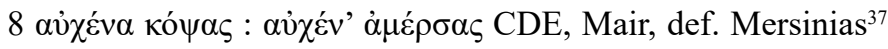

En el proemio del libro II pergeña Opiano un catálogo de los precursores de la caza ${ }^{38}$. Entre ellos se cuenta Perseo, el primero entre los mortales en dedicarse a tal actividad.

En esta ocasión atendemos a la cláusula del v. 8, donde los mss. difieren

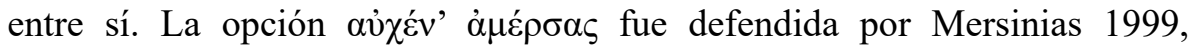
pp. 103-105, siguiendo a Schneider 1776 y a Mair 1928. Boudreaux y Papathomopoulos la descartan, razonablemente creemos. Y es que la lectura de los mss. CDE no puede ser aceptada, cuando todos los demás, incluido $\mathrm{F}$, que

${ }^{34}$ Cf. $L S J$, s. u. ỏ $\sigma \mu \eta \dot{. ~}$

${ }^{35}$ Cf. p. ej. Hom., Il. XIV 415; Od. IV 406, 442, 446, etc.; A.R. II 191, 229, 272, etc.; Nic., Th. 54, 76, 86, 425, etc., Al. 467; Opp., H. III 348, 410, IV 358, 665. Consultadas las ediciones de estos poetas a cargo de Monro y Allen $1917^{2}-1920^{3}$, Gow y Scholfield 1953, Fränkel 1961, Von der Mühll 1962³, Vian 1976-1981, Fajen 1999, Jacques 2002 y West 2000, sólo se registra ỏ $\sigma \mu$ í como v.l. o glosa en algunos mss. para Opp. H. III 348.

${ }^{36}$ Cf. p. ej. Q.S. II 564; Nonn., D. I 36, V 232, XI 499, XII 242, etc. En las ediciones de Ludwich 1909-1911, Rouse 1940, Keydell 1959, Chuvin 1976 y Vian 1963, 1976, 1995 y

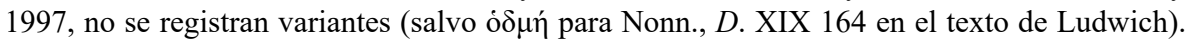

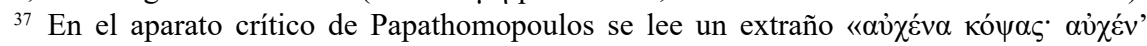

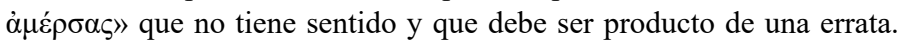

${ }^{38}$ Para este topos, cf. Hom., Il. V 49; X., Cyn. 1.1-17; Grat. 1-37, 95-107, 213-262. 


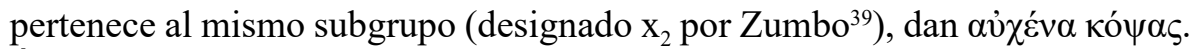
Ésta debió de ser la lectio genuina, de manera que es probable que $\mathrm{x}_{2}$, el codex deperditus del cual fueron copia CYDEF, introdujera una lectura alternativa en este punto ${ }^{40} \mathrm{y}$ este doblete fuera simplificado prefiriendo los copistas de CYDE una forma y el de F la otra.

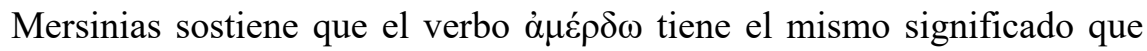

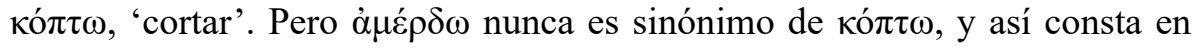
las definiciones que dan $L S J$ (s. u.) y $D G E$ (s. u.), y nosotros mismos lo hemos comprobado en un buen número de autores hexamétricos ${ }^{41}$, donde

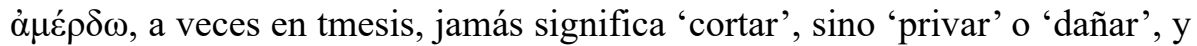
cuando se halla en un contexto que implica un corte, el complemento que lo acompaña indica el objeto que es separado del todo y no el elemento que es seccionado. Y así se observa incluso en ejemplos que cita Mersinias: Q.S. XI

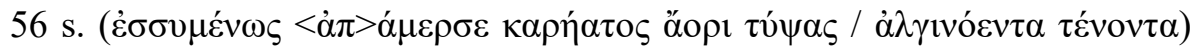

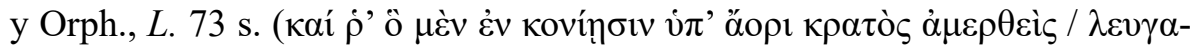

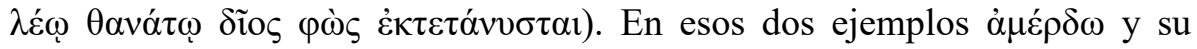

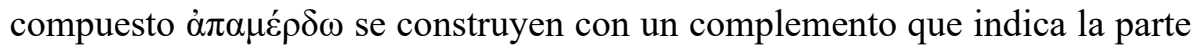

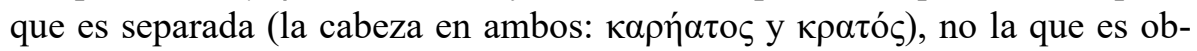

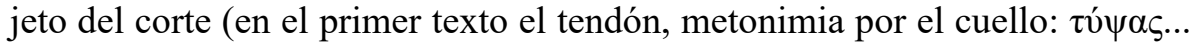
$\tau \varepsilon \dot{v} v \vee \tau \alpha$; y en el segundo el cuello de manera implícita). Sensu stricto, si se leyera $\alpha \hat{\jmath} \chi \varepsilon^{\prime} v^{\prime} \alpha \dot{\alpha} \mu \varepsilon \rho \sigma \alpha \varsigma$ en $C$. II 8, habría que entender que el cuello (no la cabeza, como es sabido) es separado del cuerpo de Gorgona.

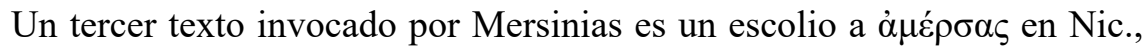

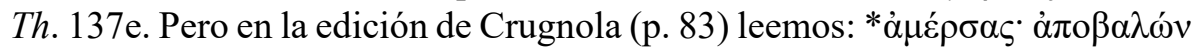

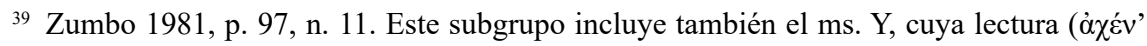
$\grave{\alpha} \mu \varepsilon \dot{\varepsilon} \sigma \alpha \varsigma$, cf. Zumbo 1981, p. 100) es omitida en el app. crit. de Papathomopoulos, probablemente por ser errónea.

40 Todos los mss. dependientes de $\mathrm{x}_{2}$ presentan algunas divergencias semejantes respecto

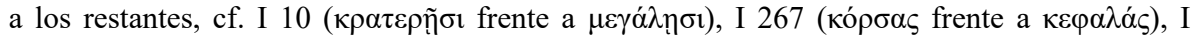

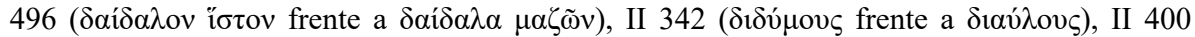

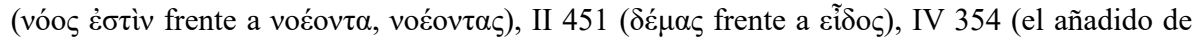

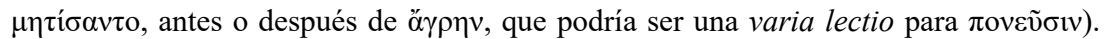

${ }^{41}$ Además de en C. I 268 y II 619, el verbo aparece en Il. XIII 340, XVI 53, XXII 58, Od. VIII 64, XIX 18, XXI 290; Hes., Th. 698, Sc. 331; A.R. I 749, I 882; Nic., Th. 137, 454; Opp., H. IV 18; Orph., L. 73, 169; Q.S. V 384, VI 243, VIII 501, XI 39, XII 413, XIV 76; Nonn., D. III 13. No se encuentra en otros autores hexamétricos también revisados (Antim., Arat., Call., Colluth., Euph., Orph. A. y H., Rhian., Triph.). 


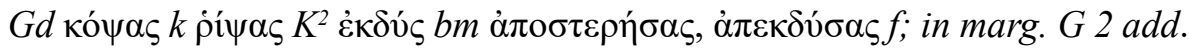

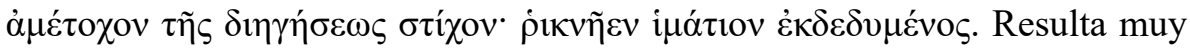

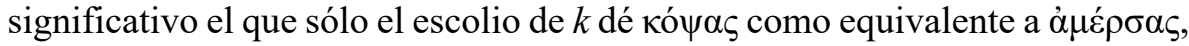
mientras que los otros le atribuyen su significado habitual o aluden de alguna otra manera a la acción y efecto de separar. En consecuencia, cabe pensar que el autor del escolio de $k$ se equivoca, si realmente pretende dar un sinónimo

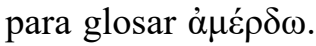

Mersinias 1999, p. 105 y n. 7, añade además ciertas consideraciones prosó-

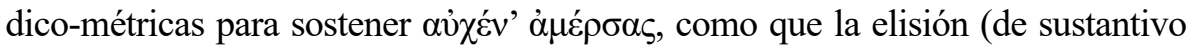
en este caso) tras la primera breve del quinto dáctilo es corriente en los Cynegetica y que el poeta sirio gusta de cerrar el verso con un participio trisílabo escandido como un baqueo $(\cup--)$, subrayando que a final de verso sólo se dan en el poema siete casos de participios espondaicos de dos sílabas. Sin embargo, uno

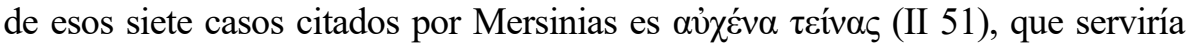

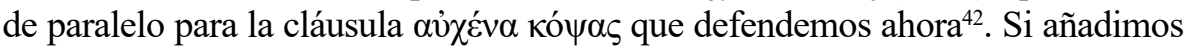

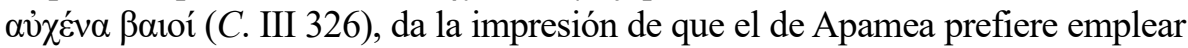

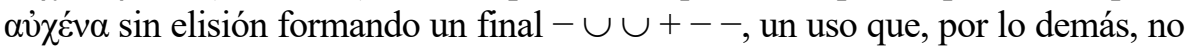
se aparta de la tradición y que reaparece en Nono de Panópolis ${ }^{43}$.

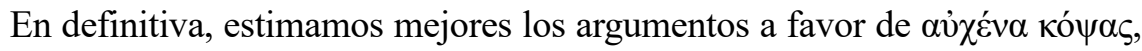
la lectura que ya había preferido Boudreaux y que, aun conociendo la argumentación de Mersinias, también es escogida por Papathomopoulos. Así, el texto se podría traducir: «Y entre los mortales el primero que inventó la caza fue quien cortó el cuello de Gorgona, el ínclito hijo del áureo Zeus, Perseo».

\section{C. III 21}

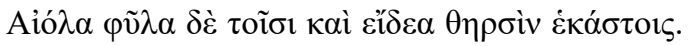

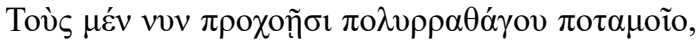

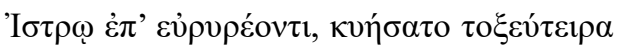

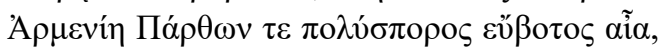

21 vov Turnebus, Bodinus : vข̃v $\mathrm{xz}$ oṽv $\mathrm{G}$

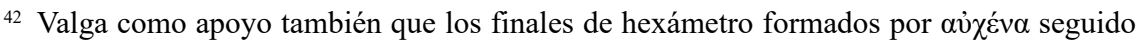
de participio están bien atestiguados antes y después de los Cynegetica. Cf. p. ej. Hom., Il. XI 146, XX 481; A.R. I 429; Nonn., D. III 229, IV 444, XI 421 etc.

${ }^{43}$ Cf. Hom., Il. V 161, V 657, XVI 339; A.R. IV 307, IV 1366; Nic., Th. 350, Al. 495; Nonn., D. I 452, II 52, II 376, III 371, VI 184, etc. 
El canto tercero, como adelanta su breve proemio (vv. 1-6), está dedicado a los depredadores, empezando por los leones. A un conciso relato de su mítico origen (vv. 8-19: los Curetes fueron metamorfoseados en leones por Crono como venganza por la protección que dieron al recién nacido Zeus, pero fueron compensados por Rea, que desde entonces los unció a su carro), sigue la descripción de tres razas (vv. 20-41: leones armenios, erembos y libios).

En $C$. III 21 todos los editores, desde Turnèbe, han optado por vov en lugar de võv. Podría este võv ser un ejemplo más de acentuación facilior que añadir a lo consignado por $L S J$ (s.u. vṽv, II.4): «even vvv is written võv in codd. vett. Pi. passim, also in S. $A j .87, T r$. 92, etc.; hence vov may freq. be restored where the sense requires it». El problema es de difícil tratamiento, como sucede en todas estas cuestiones que afectan al acento. Pero, atendiendo al sentido de la frase, creemos que aquí se puede mantener la lectura võv que dan todos los códices, salvo G.

El adverbio temporal võv no contradiría el valor acrónico o atemporal del

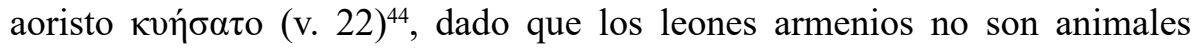
extinguidos, y así lo atestigua el uso del presente en las frases que los carac-

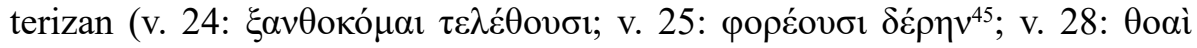

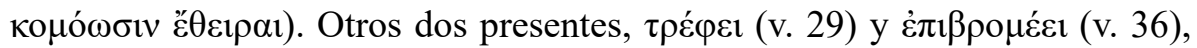

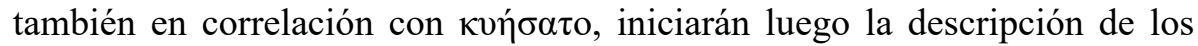
leones erembos y la de los libios en este breve catálogo de razas ${ }^{46}$.

A nuestro entender võv, al comienzo de la relación de razas, opondría todo el pasaje acerca de los leones ahora existentes a los versos anteriores, en que Opiano relata la mítica metamorfosis de los Curetes en estos animales, que tuvo lugar en un tiempo pasado. $\mathrm{Y}$ así se podría traducir el pasaje: «Variadas son las razas de estas fieras y las estampas de cada una; hay unos a los que

${ }^{44}$ Sobre los valores atemporales del aoristo (gnómico, de experiencia, etc.), cf. p. ej. Schwyzer 1966³ , pp. 283-286; Humbert 197233, pp. 144-146; Rodríguez Adrados 1992, pp. 425-428; Basile 2001, pp. 385-393. En cuanto a los adverbios en los Cynegetica, Mersinias 2016, p. 236, no estudia los de tiempo y lugar.

${ }^{45}$ Para esta lectura, presente en los mss. I K, cf. Silva Sánchez 2002, pp. 162-163. Boudreaux conjeturó $\varphi \rho \rho \varepsilon ́ o v \tau \varepsilon$, también un presente, mientras que en los otros códices se lee

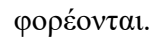

${ }^{46}$ Esta correlación de tiempos verbales se encuentra ya en los símiles homéricos, cf. Chantraine 1953, pp. 185-187. De interés por su cercanía al pasaje que nos ocupa son E., Med. 245 y Semon., fr. 1.12 ss. West. 
ahora, en la desembocadura de un sonoro río, a orillas del caudaloso Istro, paren la arquera Armenia y la tierra de los partos, fértil y rica en pastos».

\section{C. III 152}

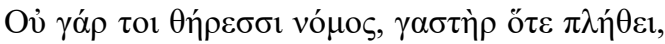

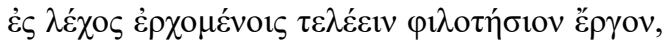

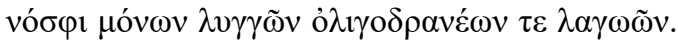

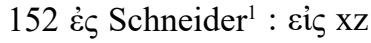

De los osos (III 139-182) se destaca su lascivia, que lleva a las hembras a forzar su vientre anticipando el nacimiento de su prole para copular cuanto antes, dado que la preñez les impide el apareamiento, como al resto de los animales, salvo a los linces y a las liebres.

En C. III 152, la corrección de Schneider 1776 (que siguen Boudreaux y Papathomopoulos, y también Mair) a la lectura unánime de los códices está motivada probablemente por el hecho de que en los poemas homéricos, a modo de norma, la preposición eí sólo es utilizada ante palabra iniciada por vocal, mientras que ante consonante inicial sólo aparece \&̧̇. Además debió de influir el inicio de verso és $\lambda \dot{z} \chi 0 \varsigma$ de C. I 500. En los Himnos homéricos se encuentra un comienzo de verso igual que este último en h.Ven. $157^{47}$, aunque también hay no pocos ejemplos del uso de $\varepsilon i \zeta \zeta$ ante consonante ${ }^{48}$. Así sucede

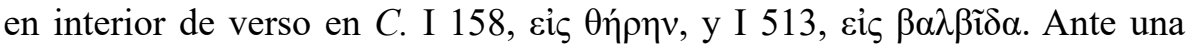
situación contradictoria como ésta, lo más adecuado, a nuestro entender, sería

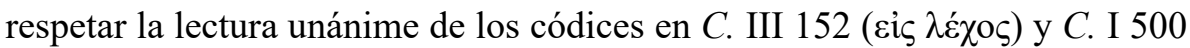
( $\dot{\varepsilon} \varsigma \lambda \hat{\varepsilon} \chi \circ \varsigma)$.

En Nono de Panópolis encontramos una situación semejante. En $D$. VII 239 (a comienzo de verso) y VIII 69 (tras la diéresis bucólica) se lee cis $\lambda \dot{\varepsilon} \chi 0 \varsigma$ en todos los manuscritos y así lo editan Ludwich 1909-1911, Keydell 1959 y Rouse 1940. Sin embargo, en $D$. VII 117 (tras la diéresis bucólica) el apara-

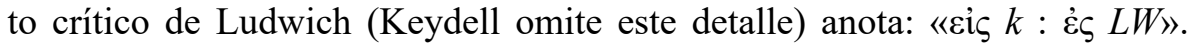
Ludwich y Rouse prefieren la primera forma en su texto, mientras que Ke-

${ }^{47}$ Como en Q.S. I 737 y en Hes., Th. 912, después de la diéresis bucólica.

${ }^{48}$ Según el texto de Allen 1912, cis ante consonante aparece en h.Cer. 450; h.Ap. 9, 345, 470; h.Merc. 12, 34, 178, 229, 257, 355, 367, 402, 480; h.Bacch. 48; h.Hom. 19.40, 26.13 (en ningún caso registra Allen una variante en el aparato crítico). 
ydell prefiere la segunda. Es decir, o se edita siempre $\varepsilon i \zeta$, o se acepta la contradicción, criterio para nosotros preferible en esta ocasión, dado que evita corregir el texto.

La traducción sería: «Pues las fieras, cuando su vientre está grávido, no tienen por costumbre llevar a cabo obras amorosas ni aparearse, excepto únicamente los linces y las débiles liebres».

8. C. III 360

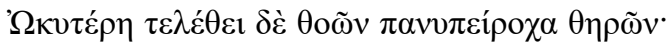

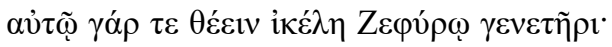

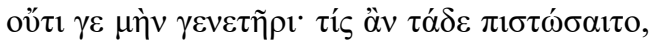

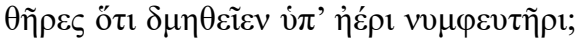

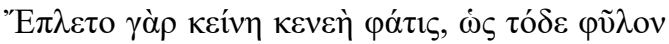

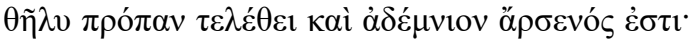

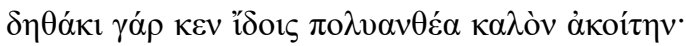

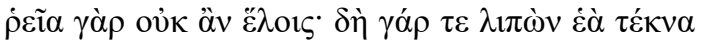

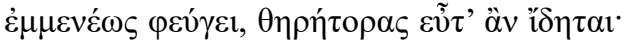

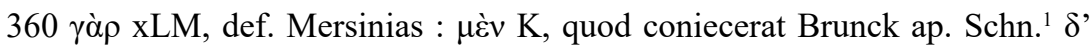
$\alpha \rho^{\prime}$ item Brunck (cf. $\left.\dot{\alpha} \lambda \lambda \alpha \dot{\alpha} \Pi\right) \delta \varepsilon \dot{\varepsilon} \gamma^{\prime}$ item Brunck

Tras encomiar la belleza de la tigresa, cuyo físico compara con el de la leona, el poeta dedica unos versos a la velocidad de los tigres en la carrera, y refiere la creencia de que descienden del Céfiro ${ }^{49}$, creencia que enlaza con otra acerca de la inexistencia de machos, pero que tiene buen cuidado de desmentir.

En C. III 360 el primer $\gamma$ ó $\rho$ es lectio mayoritaria de los manuscritos, con la excepción de $\mu \varepsilon ́ v$ en el ms. K. Con todo, en estos versos se produce una quíntuple repetición de yó $\rho$, y tal vez pensando en que las semejanzas que los versos ofrecen entre sí podrían haber inducido a los copistas a escribir erróneamente el $\gamma \alpha \dot{\alpha} \rho$ en cuestión, Brunck consideró como alternativas $\delta$ ' ö $\rho$ '

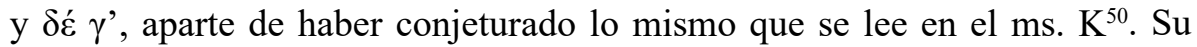
segunda propuesta fue aceptada por Schneider 1813, y la primera por Bou-

\footnotetext{
49 Ya había aludido a ello en C. I 323. Cf. Martínez 1995, pp. 91-92.

${ }^{50}$ La procedencia de las conjeturas de Brunck se lee en el app. crit. de Boudreaux: «360

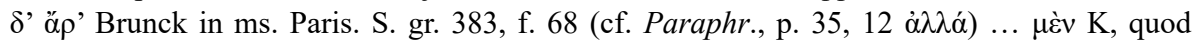

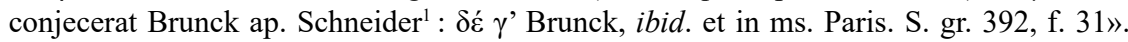


dreaux. En cambio, Mair prefiere yó $\rho$, y lo traduce así: «... but not easily couldst thou capture him; for he leaves his young and flees amain when he descries the hunters». Mersinias 1999, p. 113, defiende ese $\gamma$ ó $\rho$ al considerar que se trata de una construcción poética correcta, y que Mair acierta en su

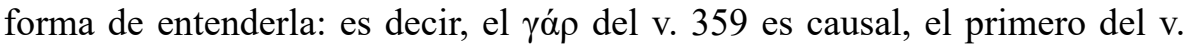
360 anticipatorio y el segundo asevera lo que se acaba de decir, es decir, da la razón de por qué no es fácil capturar al tigre macho, siendo perfectamente normal el contraste entre una idea negativa y una positiva como en el caso que nos ocupa, donde $\delta \eta ́$ tiene carácter enfático. Papathomopoulos remite a la defensa de Mersinias para editar $\gamma$ ó $\rho$.

Nosotros estamos de acuerdo con Mersinias en mantener el primer $\gamma$ ó $\rho$ del v. 360, dado que cuenta con el apoyo de la mayoría de los mss., y en su defensa, así como la de los otros yó $\rho$ que encontramos en estos versos, habla la tradición poética griega: en efecto, está documentado el uso reiterado de esta conjunción, tanto a lo largo de varios versos como dentro de un mismo ver$\mathrm{so}^{51}$. Pero no estamos de acuerdo con Mersinias en que el primer $\gamma \alpha \dot{\rho} \rho$ del v.

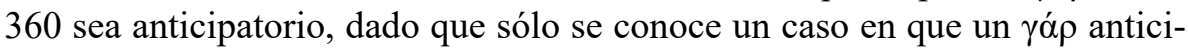
patorio es recogido por otro $\gamma \alpha \rho^{52}$. Ni compartimos el sentido adversativo que Mair le da («but»), ya que, pese a que sería lo esperado de acuerdo con la lógica (por eso en la Paráfrasis se lee $\dot{\alpha} \lambda \lambda \alpha$ ), no es un valor reconocido para

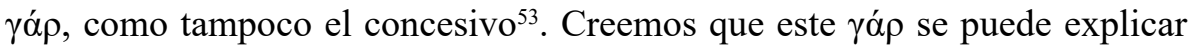
de otra manera, que permite igualmente conservarlo.

Tras desmentir en el v. 359 el rumor de la inexistencia de tigres machos ${ }^{54}$, dado que ( $\gamma \alpha$ ó causal) es posible ver frecuentemente «al policromado y bello esposo», el poeta informa en el v. 360 inmediatamente de la dificultad de capturar al macho y usa un nuevo yó $\rho$, que es aquél cuya corrección motiva estas líneas y que para Mersinias, como ya hemos dicho, tiene valor anticipatorio.

${ }^{51}$ Cf. tres $\gamma \alpha \dot{\alpha} \rho$ en tres, cuatro o cinco versos en Hom., Il. I 78-81, I 293-296, II 12-14 = II 29-31 = II 66-68, III 439-342, IV 286-288, XI 688-692, etc. En XXIV 66-72 hay cinco - tres de ellos consecutivos - en siete versos. Más ejemplos en Denniston 1954², pp. 58 y 64-65. Repetición hay, p. ej., en Hom., Il. X 57, XVIII 296, XXI 439, Od. II 163; Call., fr. 100.3 Pf.; Theoc. 12.17; Nic., Al. 627-628 (tres yó $\rho$ en dos versos); Q.S. II 158. Más casos en Denniston $1954^{2}$, pp. 58.

${ }^{52} \mathrm{Y}$ no es en poesía: X., An. III 2.11; cf. Denniston $1954^{2}$, p. 72.

${ }^{53}$ Al respecto, cf. Denniston $1954^{2}$, p. 65.

${ }^{54}$ En el verso en cuestión se expone la causa concreta de la falsedad del rumor, es decir

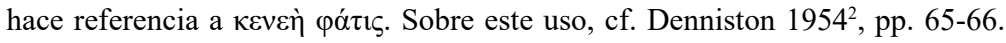




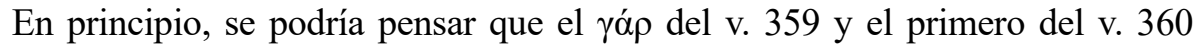
tienen valor aseverativo ${ }^{55}$ : «a menudo, en efecto $(\gamma \alpha \dot{\alpha} \rho)$, podrías ver al policromado y bello esposo; con facilidad, en efecto ( $\gamma$ óp), no lo atraparías». Pero Denniston nos pone sobre la pista de una interpretación diferente y a juicio nuestro más interesante: «The connexion of thought is sometimes lacking in logical precision ... Compression of thought is often the source of difficulty, and formal exactitude can then be achieved by supposing an ellipse ... But this, though a convenient method of exposition, is psychologically somewhat misleading $\rangle^{56}$. Ciertamente, no hay conexión lógica expresa entre los versos anteriores (rumor sobre la inexistencia de machos y desmentido, puesto que es posible verlos con frecuencia) y los que nos ocupan (escasa facilidad para capturarlos), de tal manera que se podría suponer una elipsis en el desarrollo de la exposición de los pensamientos del poeta: «dado que a menudo podrías ver al policromado y bello esposo, [circunstancia que no te servirá de mucho,] pues ( $\gamma \alpha \dot{\rho} \rho)$ con facilidad no lo atraparías». Un último $\gamma \alpha \dot{\alpha} \rho$, el segundo del v. 360, sirve para justificar la dificultad de la captura del macho, pues ( $\gamma$ ó $\rho$ ) en cuanto ve a los cazadores «abandonando sus crías, huye a toda prisa ${ }^{57}$.

Nuestra versión del pasaje sería: «Mas es de largo la más veloz de las raudas fieras, y es que en la carrera iguala al Céfiro, su progenitor, aunque en realidad no puede ser su progenitor; ¿quién podría creer esto, que las fieras puedan ser desposadas por un viento como novio? Y es que es fama infundada aquella según la cual esta tribu es toda ella mujeril y no yace con macho; dado que a menudo podrías ver al policromado y bello esposo... pues con facilidad no lo atraparías; pues de seguro abandonando sus crías, huye a toda prisa, en cuanto ve a los cazadores».

\footnotetext{
${ }^{55}$ Sobre el valor aseverativo de $\gamma \alpha \dot{\alpha} \rho$ cf. Denniston $1954^{2}$, p. 57. Para la defensa de un caso concreto, cf. Giangrande 1990, p. 9, n. 5.

${ }^{56}$ Denniston $1954^{2}$, p. 61.

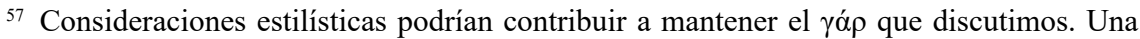
sería el neto paralelismo morfológico, sintáctico y métrico del primer hemistiquio de los vv. 359-360, lo que, unido al homeoptoton por el uso de formas verbales semejantes podría ser entendido como un juego retórico deliberado del apamense. Otra, que de este modo no se deshace una aparente secuencia progresiva: el primer $\gamma \alpha \dot{\alpha} \rho$ (v. 354) está separado por tres versos del segundo (v. 357), éste por dos del tercero (v. 359) y el tercero por uno del cuarto (v. 360), que se encuentra en el mismo verso que el quinto. La elipsis que hemos comentado como explicación del primer $\gamma \alpha \alpha \rho$ del v. 360 podría ser incluso una manera de romper la aparente monotonía provocada por los sucesivos $\gamma$ ó $\rho$ y no una inadvertencia del poeta.
} 
9. C. III 394

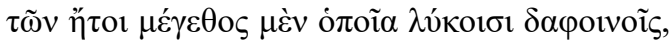

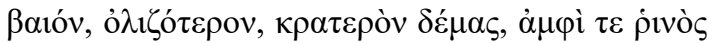

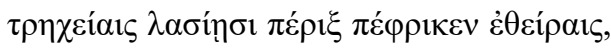

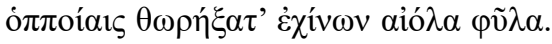

$394 \tau \varepsilon \mathrm{xz}: \delta \dot{\varepsilon}$ Schneider $^{2}$

Entre los animales que completan el canto III se encuentran los puercoespines (vv. 391-406), que se ponen a salvo de sus enemigos valiéndose de sus agudas púas.

Creemos que en $C$. III 394 lo correcto es restituir el $\tau \varepsilon$ unánime de los códices, como hace Papathomopoulos, frente al $\delta \varepsilon ́$ de Schneider 1813 seguido por Boudreaux y Mair. Parece que hay una correlación con el $\mu \varepsilon ́ v$ del verso anterior: se hace referencia, por un lado ( $\mu \varepsilon ́ v)$, al tamaño del animal comparable al de los lobos y, por otro $(\tau \varepsilon)$, a sus púas que lo hacen parecerse a los erizos. La lectura de los mss. puede ser recuperada si se tiene en cuenta que en los Cynegetica $\mu \varepsilon^{\prime} v$ no siempre está en correlación con $\delta \varepsilon^{58}$ y que los ejemplos de correlación $\mu \varepsilon ́ v-\tau \varepsilon$ son numerosos, especialmente en verso ${ }^{59}$. Según señala Denniston ${ }^{60}$, cuando $\mu \varepsilon^{v} v$ va en correlación con una partícula no adversativa, el contraste propiciado por los dos elementos es tan ligero que difícilmente se puede hablar con propiedad de un contraste y, en consecuencia, no es de extrañar que se use una partícula que exprese mera adición. Y en principio, este carácter de adición parece válido para el texto que nos ocupa.

El conjunto formado por la correlación $\mu \varepsilon ́ v-\tau \varepsilon$ contrastaría a su vez con los versos inmediatamente posteriores (397-398), introducidos por la

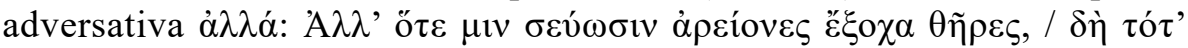

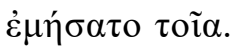

${ }^{58}$ Con $\dot{\alpha} \lambda \lambda \dot{\alpha}$ (cuando mencionamos más de un verso, la partícula introductoria de la co-

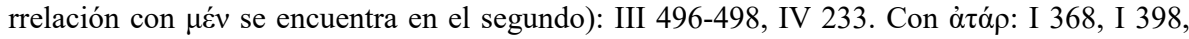

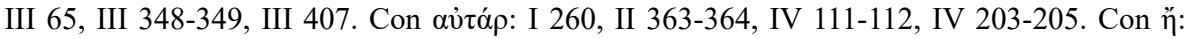

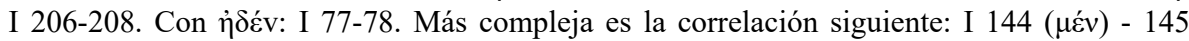

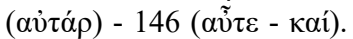

${ }^{59}$ Cf. p. ej. Hom., Il. XIX 291-293, Od. XXII 475-476; Pi., O. 6.88, 7.88 (más ejemplos de drama y prosa en $L S J$, s. u. $\tau \varepsilon$ A.I.3b).

${ }^{60}$ Denniston $1954^{2}$, p. 374 s. (Second clause introduced by non-adversative particle, III $\mu \grave{\varepsilon} \nu \ldots \tau \varepsilon)$. 
Esto es, el poeta de Apamea establecería una oposición entre aquello que en los puercoespines es comparable a otros animales (tamaño lobuno y púas de erizo) y aquello que constituye su rasgo más característico, el uso de sus púas como proyectiles ${ }^{61}$.

No habría inconvenientes, entendemos, para restituir la lectura $\tau \varepsilon$ de los manuscritos. Una traducción del pasaje, añadiendo los vv. 397-398, podría ser ésta: «Ciertamente, de un lado, su tamaño es similar al de los lobos sanguinarios, cuerpo menudo, más bien pequeño, fuerte, y la piel está erizada alrededor por la envoltura de unas púas ásperas y densas, como las que tienen por coraza las numerosas razas de los erizos; pero, cuando lo turban fieras particularmente belicosas, entonces se vale de la siguiente astucia ...».

\section{C. $I V 156$}

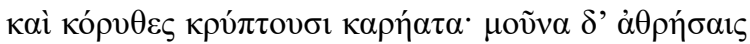

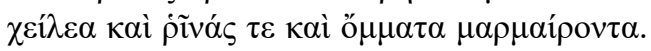

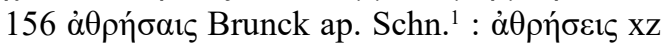

En el canto IV de los Cynegetica se describe, entre otras diversas cazas, la captura del león por parte de los cazadores etíopes, quienes luchan abiertamente con la fiera sin valerse de trampas (IV 147-211). La narración incluye detalles sobre el equipamiento de los hombres, que habrán de luchar cuerpo a cuerpo con la fiera, llevando consigo escudos y yelmos. Esos yelmos, que cubren su cabeza, sólo permiten ver boca, nariz y ojos.

Para C. IV 156 Boudreaux y Papathomopoulos prefieren el optativo

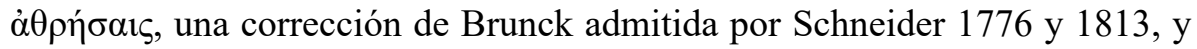
también por Mair. En primer lugar, una objeción no pequeña para aceptar $\grave{\alpha} \theta \rho \eta ́ \sigma \alpha ı \varsigma$ es que para la $2^{\mathrm{a}}$ y $3^{\mathrm{a}}$ personas del singular y la $3^{\mathrm{a}}$ del plural del optativo de aoristo sigmático Opiano de Apamea no usa las formas acabadas en - $\sigma \alpha 1 \zeta,-\sigma \alpha 1$ y $-\sigma \alpha 1 \varepsilon v$ sino las del optativo llamado por los antiguos «eólico», es decir, las terminadas en $-\sigma \varepsilon 1 \alpha \varsigma,-\sigma \varepsilon 1 \varepsilon,-\sigma \varepsilon 1 \alpha v^{62}$. De la $2^{\mathrm{a}}$ de singular en

${ }^{61}$ Para una correlación $\mu \varepsilon ́ v$ - $\alpha \lambda \lambda \alpha \dot{\alpha}$, cf. p. ej. Hom., Il. I 22 s., II 703 s.; Pi., O. 9.1 (algún otro ejemplo de tragedia y prosa en $L S J$, s. u. $\mu \varepsilon \varepsilon v$, A.II.6; véase también Denniston $1954^{2}$, pp. 5-7). Como hemos señalado en una nota precedente, es también usada en varios lugares de los Cynegetica.

${ }^{62}$ Como es sabido, las formas acabadas en - $\sigma \varepsilon 1 \alpha \varsigma,-\sigma \varepsilon 1 \varepsilon,-\sigma \varepsilon 1 \alpha v$ son las usadas regularmente en ático. Su origen es enigmático y su denominación como optativo «eólico» no parece 


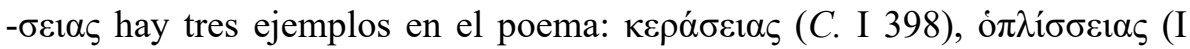
514) y $\alpha \theta p \eta ́ \sigma \varepsilon 1 \alpha \varsigma$ (III 345), precisamente el mismo verbo que tenemos en IV 156. En cambio no hay ningún ejemplo de la forma en $-\sigma \alpha 1 \varsigma^{63}$.

Sin embargo, el futuro à $\theta \rho \eta ́ \sigma \varepsilon 1 \varsigma$, lectura unánime de los mss., encuentra justificación en la sintaxis y en la tradición de la poesía didáctica griega. En este tipo de poesía el futuro de indicativo, en su segunda persona del singular, es usado con frecuencia para dirigirse al destinatario del poema, real o ficticio, concreto o general. En esos futuros se observan varios valores, pues los poetas los utilizan para presentar las enseñanzas que obtendrán de su obra o las ventajas que reportan sus preceptos, y también para impartir consejos ${ }^{64}$. Pero además se emplea para introducir un elemento descriptivo, como ahora. Este último valor no abunda, pero está bien documentado, pues lo encontramos en Arat. 222, donde se recuerda que la fuente Hipocrene se halla cerca

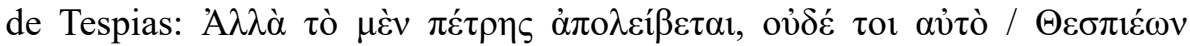

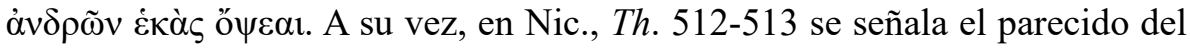

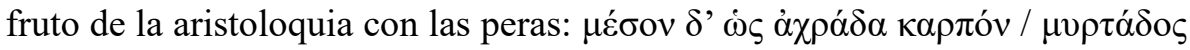

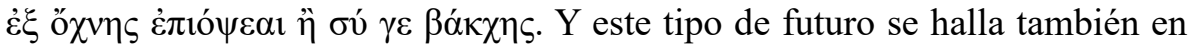
Orph., L. 296 (cf. v. 387) cuando se describe una de las variedades de la

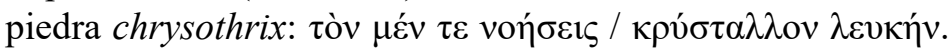

Los futuros de estos tres pasajes, así como el de los Cynegetica, parecen cercanos a los futuros tradicionalmente llamados «futuros descriptivos» ${ }^{65}$, uso que también se encuentra en alguna descripción geográfica de Heródoto. Humbert apunta la existencia del futuro que indica «possibilité permanente» ${ }^{66}$. El futuro empleado por Opiano reflejaría dicha posibilidad, añadiendo cierto matiz de cortesía (un rasgo no extraño en la poesía didáctica) y consiguiendo, frente

muy razonable. En Homero conviven ambas series de formas, aunque son más numerosos los optativos en $-\sigma \varepsilon 1 \alpha \varsigma,-\sigma \varepsilon 1 \varepsilon,-\sigma \varepsilon 1 \alpha v$, cf. Chantraine 1948, pp. 464-465. Agradecemos a uno de los revisores anónimos de este trabajo la sugerencia de este argumento.

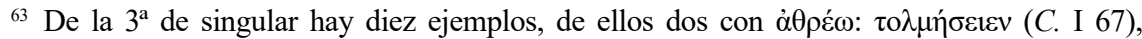

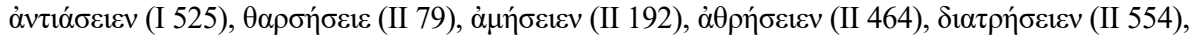

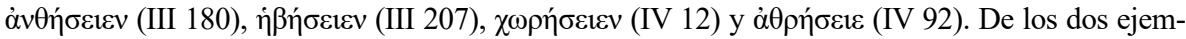

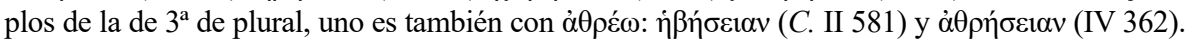

${ }^{64}$ P. ej. Hes., Op. 401-403, 475 ss., 480-482; Emp. fr. 111 DK; Nic., Th. 35, 56, 518, 551, 593, 921 ss., 927 ss., Al. 278, 566, fr. 74.40 y fr. 79.

${ }^{65}$ Sobre este tipo de futuro, cf. Magnien 1912, p. 170, donde se citan varios ejemplos de Heródoto (II 29.3-5, II 97.2, IV 28.1, V 52.2).

${ }^{66}$ Humbert $1972^{3}$, p. 151. 
al optativo, una mayor viveza. Semejante afirmación del poeta tal vez proceda de su experiencia personal o de una versión muy directa de los hechos. Cabe recordar que, aunque se ha criticado el contenido fantasioso o disparatado de bastantes pasajes de los Cynegetica, se admite que las descripciones de caza del libro IV referidas a león, leopardo y oso contienen una buena dosis de verismo ${ }^{67}$.

Ciertamente, reconocemos que este futuro sería único en los Cynegetica, pero en este poema a menudo la excepción es regla. La traducción de estos versos sería: «Y cascos cubren sus cabezas. Y sólo verás labios, narices y ojos relucientes $»^{68}$.

\section{C. $I V 198$}

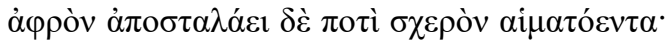

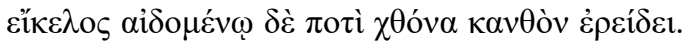

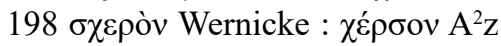

La lectura que nos interesa, inserta en los versos en que el león, tras enfrentarse con los cazadores etíopes, está vencido y a punto de desplomarse, aparece sólo en los mss. de la familia $\mathrm{z}$, así como en $\mathrm{A}_{2}$, cuyas lecturas están relacionadas con este grupo ${ }^{69}$. En esos mss. se lee $\chi \dot{\varepsilon} \rho \sigma o v$, término inconveniente por su significado e incorrecto por obvias razones métricas. Fueron postuladas varias alternativas, $\sigma \chi \varepsilon \rho o ́ v$ por Wernicke (elegida por Boudreaux y Papathomopoulos)

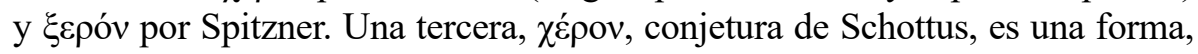
creemos, inexistente, además de métricamente inaceptable ${ }^{70}$.

La corrección de Wernicke plantea inconvenientes de consideración. El

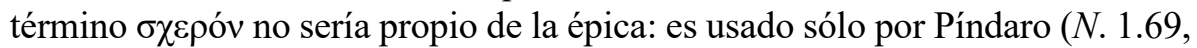
$11.39, I .6 .22)$, únicamente en dativo y en una construcción singular, غ̇v $\sigma \chi \varepsilon \rho \tilde{~}$ ('en línea, sucesivamente', cf. LSJ, s. u.); este sintagma se entendió posterior-

${ }^{67}$ Cf. Keydell 1939, col. 706; Effe 1977, p. 182.

${ }^{68}$ En traducción de Turnèbe 1555: «et cassides tegunt capita: sola autem cernes / labra, et nasum, et oculos micantes».

${ }^{69} \mathrm{Cf}$. el comentario a $C$. I 147. En la familia x se habría producido una contracción de los vv. 198-199, atribuible a la presencia de $\delta \dot{\varepsilon} \pi$ o $\tau i ́$ en ambos, como hacen constar Boudreaux y Papathomopoulos.

${ }^{70}$ Las propuestas de Spitzner y Schottus faltan en el app. crit. de Papathomopoulos, pero

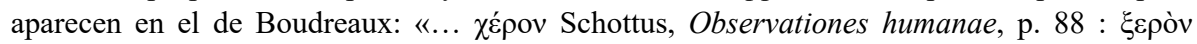
Spitzner, de versu herö̈co, p. 46». 
mente como un adverbio $(\dot{\varepsilon} v \sigma \chi \varepsilon \rho \omega ́)^{71}$. Por otra parte, en el léxico de Hesiquio

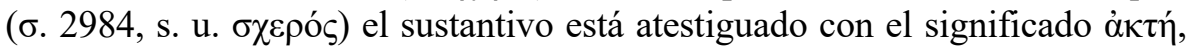

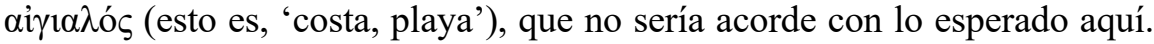

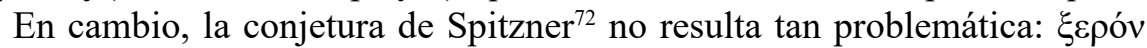

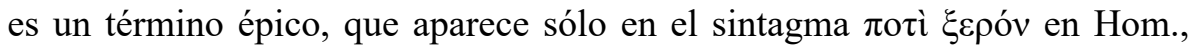
$O d$. V 402, A.R. III 322 y $A P$ VI 304 y IX 381 (epigrama que es, de hecho,

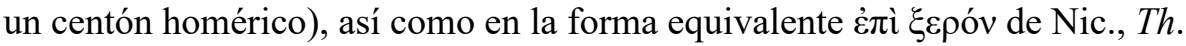
704, ocupando siempre la misma sedes métrica que en los Cynegetica. Del significado del término, no obstante, se derivan ciertas dificultades, dado que

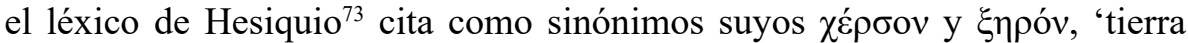
firme', sentido que si bien no encaja del todo en el contexto de los Cynegetica ${ }^{74}$, podría dar lugar a una interpretación laxa como 'tierra, suelo', tal como el pasaje requiere. En cambio, los escoliastas, con referencia al pasaje homérico

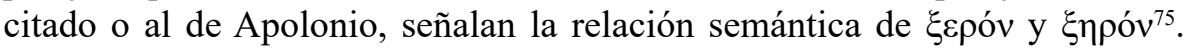
Atendiendo, pues, a la dificultad interpretativa que suponía ya para los antiguos esta palabra, no sería descabellado creer que el de Apamea la interpretó con cierta libertad, dándole un sentido amplio como 'tierra, suelo'.

Habida cuenta de todos los factores relacionados, parece más probable

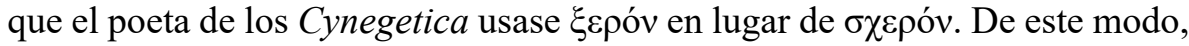
consideramos preferible la conjetura de Spitzner, pudiendo traducirse así estos dos versos: «Y derrama sangrienta espuma en el suelo, mientras, semejante a un hombre avergonzado, baja su mirada a tierra».

${ }^{71}$ Cf. Antim. 20.5 Wyss; A.R. I 912 (así lo editan, por ejemplo, Fränkel 1961 y Vian 1976-1981).

${ }^{72}$ Según Spitzner 1816, p. 46 s., razones métricas llevarían a preferir $\chi \varepsilon \dot{\varepsilon} \rho \sigma o v$ o $\xi \varepsilon \rho o ́ v:$ «etenim poetae prout versus necessitas exigit, modo $\chi \dot{\varepsilon} \rho \sigma o v$ modo $\xi \varepsilon \rho o ́ v ~ s c r i b u n t »$.

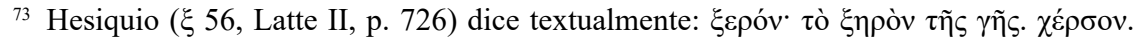

${ }^{74} C$. IV 198 presenta grandes semejanzas con $C$. III 370, verso casi idéntico hasta la

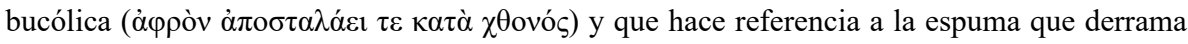
sobre el suelo el jabalí.

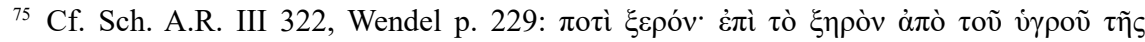
$\theta \alpha \lambda \alpha ́ \sigma \sigma \eta \zeta ;$ Sch. Hom., Od. V 402 Dindorf (nótese que este escolio indica que el sustantivo

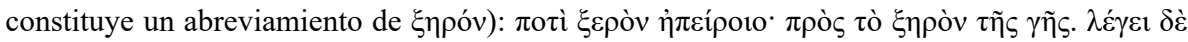

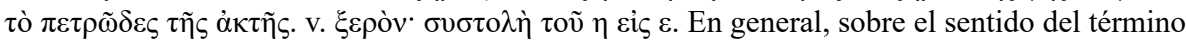
en Homero, cf. Ebeling 1885, s. u. A su vez, Eust. Comm ad Homeri Od., 1.223.16 ss., a partir de esa relación, apunta el parentesco con el verbo $\xi \hat{\varepsilon} \omega$ en consideración a la facilidad con que son alisados los objetos secos (cf. Comm ad Hom. Il. 3.232.1) y menciona la posibilidad

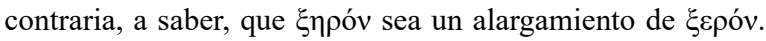


12. C. $I V 295$

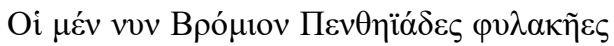

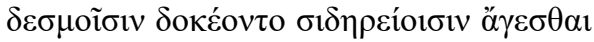

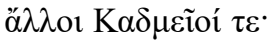

295 vvv Turnebus, Bodinus : vṽv Abz om. G in lacuna

El canto IV de los Cynegetica contiene una larga digresión etiológica (vv. 233-315) sobre el origen de las panteras y el de su afición al vino. Estos animales proceden de la metamorfosis de las mujeres que acompañaban a Dioniso y de ahí su devoción por esta bebida. El clímax del excurso se encuentra en el enfrentamiento entre el dios y Penteo, que, convertido en toro, será despedazado por las compañeras de Dioniso, transformadas en panteras.

Para $C$. IV 295 se plantea un problema textual similar al comentado para III 21: la corrección del adverbio võv que se lee en casi todos los códices ${ }^{76}$. Y siendo, como aquél, un problema de difícil tratamiento, nuevamente entendemos que la cantidad larga de la $v$ es admisible y también el sentido temporal del adverbio usado con tiempo de pasado, en este caso un imperfecto

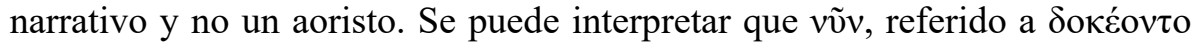
óy $\delta \sigma \theta \alpha \mathrm{l}$ (v. 296), confiere al relato un cierto sentido de inmediatez y viveza ('ya, justo entonces'), uso acaso inspirado en alguno de los numerosos ejemplos épicos de vĩv con tiempo de pasado ${ }^{77}$.

Estos versos se podrían traducir así: «Por su parte, ya los guardianes de Penteo y los otros cadmeos estaban decididos a llevarse a Bromio con ataduras de hierro».

\section{BIBLIOGRAFÍA}

Agosta, G. 2003: «Due note testuali al proemio dei Cynegetica I 26, 32-34», Eikasmos 14, pp.133-160.

Agosta, G. 2005: «Ps. Oppiano, Cynegetica 1.26: nota sulla storia del testo», Lexis 23, pp. 325-338.

\footnotetext{
${ }^{76}$ Papathomopoulos omite la lectura $\delta \eta ́$ del ms. I, que está en cambio en el app. crit. de Boudreaux.

${ }^{77}$ En ellos, no obstante, se hace referencia a hechos inmediatamente anteriores, cf. $L S J$, s. u. vṽv, I.2. Aunque abundan los ejemplos de este adverbio acompañando un aoristo (Hom., Il. III 439, XIII 772, Od. I 43), también aparece con imperfecto (Il. II 681).
} 
Agosta, G. 2009a: «Note in margine ad una recente edizione dei Cynegetica di Oppiano», Athenaeum 97, pp. 273-283.

Agosta, G. 2009b: Ricerche sui Cynegetica di Oppiano, Amsterdam.

Allen, Th. W. 1912: Homeri Opera V, Oxford (reimpr. 1983).

Almirall, J. 1996: Arat. Fenòmens, Barcelona.

Bartley, A. N. 2004: reseña de Papathomopoulos 2003, ExClass 8, pp. 223-226.

Basile, N. 2001: Sintassi storica del greco antico, Bari.

Benedetti, F. 1973: reseña de W. Schmitt, 1969, RFIC 101, pp. 514-516.

Bernabé, A. 1992: Manual de crítica textual y edición de textos griegos, Madrid.

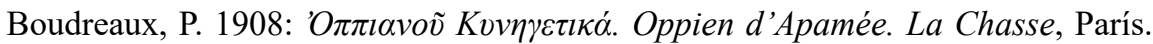

Calvo Delcán, C. 1990: Opiano, De la caza; De la pesca. Anónimo, Lapidario órfico, Madrid.

Chantraine, P. 1948: Grammaire homérique. I: Phonétique et Morphologie, París.

Chantraine, P. 1953: Grammaire homérique. II: Syntaxe, París.

Chuvin, F. 1976: Nonnos de Panopolis. Les Dionysiaques III-V, París.

Cipolla, P. 2006: «Nota a Opp. Cyn. 382-390», Lexis 24, pp. 517-521.

Denniston, J. D. 1954: The Greek Particles, Oxford.

Ebeling, H. 1885: Lexicon Homericum, Leipzig (reimpr. Hildesheim, 1987).

Effe, B. 1977: Dichtung und Lehre. Untersuchungen zur Typologie des antiken Lehrgedichts, Múnich.

Erren, M. 1971: Arat. Phainomena, Múnich.

Fajen, F. 1995: Noten zur handschriftlichen Überlieferung der Halieutika des Oppian, Maguncia y Stuttgart.

Fajen, F. 1999: Oppianus. Halieutica. Oppian. Der Fischfang, Stuttgart y Leipzig.

Fränkel, H. 1961: Apollonii Rhodii Argonautica, Oxford.

Giangrande, G. 1973: reseña de Schmitt 1969, CR 23, pp. 86-87.

Giangrande, G. 1990: «The cure for love in Theocritus' Idyll XI», AMal 13.1, pp. 5-9.

Giomi, E. 2003: «Ps. Oppiano, Cynegetica III 53-55 e la zampa "narcotizzante" del leone», Maia 55, pp. 537-544.

Gow, A. S. y Scholfield, A. F. 1953: Nicander. The poems and poetical fragments, Cambridge.

Humbert, J. 1972³: Syntaxe grecque, París.

Jacques, J. M. 2002: Nicandre. Euvres. Les Thériaques, París.

Keydell, R. 1939: «Oppianos», RE XVIII-1, cols. 703-708.

Keydell, R. 1959: Nonni Panopolitani Dionysiaca I-II, Berlín.

Kidd, D. 1997: Aratus: Phaenomena, Cambridge.

L'Allier, L. 2009: Arrien et Oppien d'Apamée, L'art de la chasse. Cynégétiques, París.

Lehrs, K. 1837: «Dissertatio V. De Halieuticorum et Cynegeticorum discrepantia», Quaestiones epicae, Königsberg (reimpr. Hildesheim, 1977). 
Ludwich, A. 1909-1911: Nonnus. Dionysiaca I-II, Leipzig.

Ludwich, A. 1910: reseña de Boudreaux 1908, BPhW 9, cols. 257-261.

Magnien, V. 1912: Le futur grec II, París.

Mair, A. W. 1928: Oppian. Colluthus. Tryphiodorus, Cambridge, Mass. y Londres.

Martin, J. 1956: Arati Phaenomena, Florencia.

Martínez, S. 1995: «Els amors difícils dels animals», $A F B$ 18, pp. 85-95.

Martínez, S. y Silva Sánchez, T. 2003: «Opiano, ¿un poeta o dos?», $A C$ 72, pp. 219-230.

Martínez, S. 2010: reseña de Agosta 2009b, BMCR 2010.08.70. URL: < https://bmcr. brynmawr.edu/2010/2010.08.70>

Mersinias, S. 1999: «Notes on the Cynegetica of Ps. Oppian», Minerva 13, pp. 103-125.

Mersinias, S. 2016: «On adverbs in the Cynegetica of ps.Oppian», Myrtia 31, pp. 235-267.

Mioni, E. 1985: Codices Graeci manuscripti Bibliothecae Divi Marci Venetiarum, II, Roma.

Monro, D. B. y Allen, Th. W. $1917^{2}-1920^{3}$ : Homeri opera II-IV, Oxford (reimpr. 1978-1980).

Papathomopoulos, M. 2003: Oppiani Apameensis Cynegetica. Eutecnii Sophistae Paraphrasis metro soluta, Leipzig.

Rebmann, O. 1918: Die sprachlichen Neuerungen in den Kynegetika Oppians von Apamea, Basilea.

Rodríguez Adrados, F. 1992: Nueva sintaxis del griego antiguo, Madrid.

Rouse, W. H. D. 1940: Nonnos. Dionysiaca I-III, Cambridge, Mass. y Londres (reimpr. 1984-1985).

Schmitt, W. 1969: Kommentar zum ersten Buch von Pseudo-Oppians Kynegetika, diss. Münster.

Schneider, J. G. 1776: Oppiani poetae Cilicis de venatione libri IV. et de piscatione libri V. Cum paraphrasi Graeca librorum de aucupio, Estrasburgo.

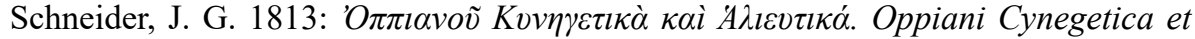
Halieutica, Leipzig.

Schwyzer, E. 1966³ : Griechische Grammatik, II, Múnich.

Silva Sánchez, T. 2002: Sobre el texto de los Cynegetica de Opiano de Apamea, Cádiz.

Spitzner, F. 1816: De versu Graecorum herö̈co, Leipzig.

Turnèbe, A. 1555: Oppiani Anazarbei De piscatu libri V. De venatione libri IIII, París.

Vian, F. 1963: Quintus de Smyrne. La suite d'Homère I, París.

Vian, F. 1976: Nonnos de Panopolis. Les Dionysiaques I-II, París; 1995: Nonnos de Panopolis. Les Dionysiaques XI-XIII, París; 1997: Nonnos de Panopolis. Les Dionysiaques XXX-XXXII, París.

Vian, F. 1976-1981: Apollonios de Rhodes. Argonautiques I- IV, París. 
Von der Mühll, P. 1962: Homeri Odyssea, Stuttgart.

Wackernagel, J. 1950²: Vorlesungen über Syntax I, Basilea.

West, M. L. 2000: Homerus. Ilias, vol. alterum, Stuttgart y Leipzig.

Zumbo, A. 1981: «Un nuovo manoscritto dei Cynegetica pseudo-oppianei», BollClass 2, pp. 95-103.

Fecha de recepción de la primera versión del artículo: 30/08/2019 Fecha de aceptación: 18/12/2019

Fecha de recepción de la versión definitiva: 22/01/2020 